\title{
A novel modification of the Endorectal Advancement Flap for complex anal fistulas: surgical technique and outcomes
}

Hassan Al-Turaihi ( $\square$ hassan.turaihi@gmail.com )

UH Cleveland Medical Center https://orcid.org/0000-0001-8418-7869

Elizabeth Blears

Allegheny Health Network

Kavin Sugumar

UH Cleveland Medical Center

Ganesh Deshmukh

Beaumont Hospital

Research article

Keywords: Fistula-in-Ano, Endorectal Flap, Fecal incontinence

Posted Date: November 30th, 2020

DOI: https://doi.org/10.21203/rs.3.rs-43719/v3

License: () (7) This work is licensed under a Creative Commons Attribution 4.0 International License. Read Full License

Version of Record: A version of this preprint was published at International Surgery on January 1st, 2021. See the published version at https://doi.org/10.9738/INTSURG-D-21-00008.1. 


\section{Abstract}

\section{Background:}

Fistula-in-ano is a common problem encountered by surgeons which can be classified as either simple or complex. Complex fistulas (CF) cause higher morbidity and are much more challenging to treat. Although numerous treatment options are available for $\mathrm{CF}$, none are proven to be $100 \%$ effective. The endorectal advancement flap (EAF) procedure was developed as an alternative to conventional surgical treatments for CF. Herein, we describe a novel modification of the EAF procedure along with surgical outcomes in terms of recurrence, fecal incontinence and factors associated with flap failure.

\section{Methods:}

A retrospective review of patients with CF who underwent EAF between 2004-2019 was done. The conventional EAF procedure was modified by performing transverse imbrication of the internal sphincter over the internal fistula opening. The incidence of post-operative recurrence and fecal incontinence were calculated from chart documentation at the last available date of follow-up. Also, the association between various clinical and demographic factors and post-operative flap failure were using statistical significance at alpha of 0.05 .

Results:

With a median follow-up of 6.6 months (range: 3.3-24 months), 99 patients with CFs underwent a modified EAF. Of these, 93\% (92/99) had a successful procedure, 7\% (7/99) experienced recurrence and 1\% (1/99) experienced new-onset fecal incontinence. Systemic steroid or immunomodulatory therapy use $(p=0.001)$ and patients with diagnosed inflammatory bowel disease $(p<0.0001)$ were associated with increased rate of recurrence.

\section{Conclusion:}

EAF with transverse imbrication of the internal opening using interrupted, absorbable suture is an effective technique to treat complex or recurrent anal fistulas. It is associated with a low risk of recurrence (7\%) and fecal incontinence (1\%) and a valid treatment option for CFs.

\section{Background}

Perianal fistulas are one of the most common conditions treated by colorectal and general surgeons. ${ }^{1,2}$ Although anal fistulas are not life-threatening, they result in debilitating pain and soiling, which negatively affect quality of life..$^{3,4}$ In most instances, history of perianal abscess precedes fistula-in-ano. ${ }^{1,2,5}$ Although, $50-70 \%$ of patients resolve with surgical drainage, 30-50\% progress to develop perianal fistula. which supports the theory that fistulas are commonly caused by cryptoglandular abscesses that fail to heal. ${ }^{1,2,5}$ However, the progression of abscess to fistula is more common in patients with other underlying conditions, such as Inflammatory Bowel Disease (IBD) or malignancy. 1,2 Thus, addressing the underlying cause is important to preventing recurrence. ${ }^{1,2}$

Simple fistulas are low-lying within the anal canal, close to the anal verge, and are associated with low risks of fecal incontinence as they are superficial to the external anal sphincter. ${ }^{5}$ They can be treated by either fistulotomy or fistulectomy, with high rates of successful outcomes. ${ }^{5}$ On the contrary, complex fistulas (CF) are located deeper in the anal canal (or "high" in the pelvis) to include the rectum, and can involve more than $30 \%$ of the circumference of the external anal sphincter. ${ }^{5} \mathrm{CFs}$ can communicate with adjacent organs, such as the vagina, and often develop in conjunction with a history of radiation or IBD. ${ }^{6}$ They can also be due to iatrogenic injury after colorectal surgery or obstetric trauma. ${ }^{5}$ Because of the diversity of etiologies and complexity of condition, there have been a wide variety of surgical procedures developed to treat

CFs, including ligation of the fistula tract (LIFT), ${ }^{7}$ video-assisted anal fistula treatment (VAAFT) ${ }^{8,9}$ fistula laser closure 
(FiLAC), ${ }^{10}$ and endorectal advancement flap (EAF). ${ }^{11,12}$ However, these are associate with some risk of fecal incontinence due to manipulation of the tissues around the external anal sphincter. ${ }^{11,12}$ While there are non-surgical options, such as fibrin glue, plugs or stem cell pastes, that have minimal risk of fecal incontinence, they have lower success rate compared to surgical options. ${ }^{13,14}$ Thus, at present, there is no ideal treatment strategy for CF. ${ }^{1,2}$

EAF is one of the most common procedures performed for CFs. It was first reported by Nobel in 1902 for the treatment of rectovaginal fistulas that commonly resulted from obstetric trauma. ${ }^{11,15}$ It was later modified using a flap of rectal tissue to close the tract between the source of the fistula deeper in the cryptoglandular tissue and its opening to the anal mucosa. ${ }^{11,15,16}$ Flaps can be tongue-shaped, rhomboid, or elliptical and can include the rectal mucosa alone, or extend deeper to include the submucosa, partial layers of the internal anal sphincter or the entire thickness of the internal anal sphincter. ${ }^{1,2}$ Traditionally, the opening of the fistula within the rectum is either left open to heal by secondary intention or closed with simple, interrupted, or figure-of-eight sutures. ${ }^{11,15,16}$ In addition to covering with a flap, the fistula tract can be treated with curette or coring out. ${ }^{1,2}$ Although technically complex, the advantage of the EAF is that the sphincter complex is left intact, and thus, EAF has a lower risk of fecal incontinence when compared to other surgical options. ${ }^{1,2}$ After study for over a century, EAF has an accepted recurrence rate of 7-48\% with a risk of fecal incontinence of $15-20 \% .{ }^{1,2}$ However, the optimal thickness of the flap and technique for CFs fistulas is unknown.

Herein, we describe a novel modification of the EAF procedure along with surgical outcomes in terms of recurrence and fecal incontinence post-surgery. We also examine the factors associated with recurrence.

\section{Methods}

A retrospective chart review of patients diagnosed with complex rectal or anal fistulas who underwent an EAF procedure by the Principal Investigator between January 2004 and February 2019 was done. This study was approved by the Institutional Review Board under Protocol \# 2019-233.

\section{Inclusion and Exclusion Criteria:}

Patients who presented with CFs and underwent evaluation for EAF placement were included. A CF was defined according to the Garg Classification of severe fistulas in which fistulotomy should not be attempted (Grade III, IV, V). ${ }^{17,18}$ These included as a high linear transsphincteric fistula according(involving an estimated $>1 / 3$ of the sphincter, a fistula associated with IBD, previous sphincter injury, post radiation exposure or an anterior fistula in a female), a transsphincteric fistula with either abscess, multiple tracts or a horseshoe component or interssphincteric supralevator or extrasphincteric extension. ${ }^{19}$ Due to discrepancy in fistula classification found historically in the literature, the newer Garg classification was compared to older classification systems (Parks ${ }^{5}$ and St James University ${ }^{20}$ ) to better assess how our population compares to the those previously reported. CFs were diagnosed and initially assessed by physical examination and confirmed by intraoperative exam under anesthesia (EUA). If fistula tract or anatomy was unclear by initial clinical exam, Magnetic Resonance Imaging (MRI) was obtained to further define anatomy and classify the fistula-in-ano and aid with surgical planning. All patients who were included were confirmed by MRI and/or EUA as having CFs, and therefore not amenable to simple fistulotomy.

\section{Data Collection:}

Patient demographic information including age, sex, race, body mass index (BMI), number and type of previous perianal surgeries, history of smoking, systemic steroid use, immunomodulator or immunosuppressive use, IBD (Crohn's Disease, Ulcerative Colitis (UC) or indeterminant colitis), Chronic Obstructive Pulmonary Disease, Congestive Heart Failure, Coronary Artery Disease, Type II Diabetes Mellitus, Hypertension, and Chronic Kidney Disease were recorded if listed as a diagnosis within the patient's chart at the time of initial pre-op clinical evaluation. Immunomodulator or immunosuppressive use was defined as those who before or at the time of surgery received the current FDA approved agents for the treatment of Crohn's 
or UC (including, mercaptopurine, azathioprine, infliximab, or any novel monoclonal antibodies), or chemotherapy for alternative cancer, or immunosuppression for a history of solid organ transplantation. The etiology of fistula-in-ano including cryptoglandular, Crohn's disease, UC, post-obstetric fistula, radiation-induced, untreated carcinoma, or Hidradenitis Suppurativa was noted. Additional information regarding the surgical procedure was noted including date of surgery, date of subsequent follow-up visits and date of last follow-up, presence of recurrence of symptoms post-surgery, and subsequent surgical interventions (such as diversion, fistulectomy or repeat EAF). The presence of fecal incontinence, before and after surgery, was assessed at time of history taking during outpatient clinical exams.

\section{Outcomes:}

Primary outcomes were fistula recurrence and new-onset fecal incontinence after EAF surgery. Recurrence was defined as "the presence of an abscess or purulent drainage from the primary fistula area after at least 6 weeks of healing from EAF". Fecal incontinence was defined as "difficulty controlling stools (soiling) during follow-up as described by the patient." ${ }^{1,2}$ Fecal incontinence was assessed by thorough history and any complaints of difficulty controlling stool or flatus was extracted from the patient's medical record. Healing from surgery was defined as absence of pain impairing activities of daily living, drainage, soiling or signs of persistent inflammation consistent with concern for wound infection.

\section{Endorectal Advancement Flap: Technical details}

\section{Preoperative and intraoperative patient preparation:}

All patients received full bowel preparation prior to surgery. On the day of the surgery, a fleet or saline enema was given to the patient based on tolerability. All procedures were performed in the outpatient setting under spinal or general anesthesia. Patients that had fistulas with an anterior lying internal opening were positioned in a prone jack-knife position, whereas those with a posterior internal opening were placed in a lithotomy position.

\section{Description of the surgical technique:}

Initial exposure of the surgical field is provided using a Park's anal retractor, which is later exchanged for a large or mediumsized Sawyer or Hill-Ferguson retractor to decrease tension on the lateral edges during flap closure. Since local anesthetic injection around the future flap site could potentially compromise flap perfusion, local anesthetic is not administered. The rectal mucosa is dissected using needle-tip electrocautery, ensuring a flap base that is three times wider than the apex of the flap (Figure 2A \& 2B). Once the flap is created, the internal opening is closed by imbricating the internal sphincter using multiple transverse interrupted 2-0 Vicryl sutures (Figure $2 \mathrm{C}$ ). This modification not only serves to close the internal sphincter opening, but it also decreases tension on the flap during the closure. The flap is secured over the center of the defect by suturing the inferior edge of the flap with multiple interrupted 3-0 Vicryl sutures to the internal sphincter and anoderm distally to control the interssphincteric tract (Figure $3 \mathrm{~A}$ ). Compared to running sutures, interrupted suture placement is believed allow drainage underneath the flap that would otherwise collect and impair healing. The lateral edges of the flap are then closed with 3-0 Vicryl sutures, with lateral bites that measured less than 3mm (Figure 3 B).

All external fistula openings and granulation tissue are debrided in a core-out fashion, and the fistula tract(s) are excised to the border of the external sphincter muscle (Figure 4A, 4B \&4C). Post-operatively, patients are instructed to avoid strenuous activity and provided with non-narcotic analgesia for 7 days. Patients are followed-up in the clinic at 1-2 weeks postoperatively and approximately every 3 months thereafter until complete healing. Fiber supplements are provided to maintain regular bowel movements and avoid constipation during post-operative healing.

\section{Statistical Analysis:}

Continuous data were analyzed for normality using the Shapiro-Wilki's test. Normally distributed continuous variables were analyzed for statistical significance using Student's t-test and reported as means with standard deviation, whereas non- 
normally distributed continuous variables were analyzed for statistical significance using Mann-Whitney $U$ tests and reported as median with $25^{\text {th }}-75^{\text {th }}$ interquartile range (IQR). Categorical variables were compared using Pearson chi-squared test. Statistical analysis was performed using StataSE software (StataCorp. 2019. Stata Statistical Software: Release 16. College Station, TX: StataCorp LLC), and statistical significance was defined as alpha $<0.05$. Figures were created using Adobe Illustrator version 24.0.1.

\section{Results}

Records from 111 patients between 2004-2019 that underwent evaluation for EAF for CF were reviewed, with a median follow-up of 6.6 months (IQR: 3.3-24 months). The symptoms were assessed, and the operative site was examined by the surgical team at the same hospital at 1-2 weeks post-surgery and then every 3 months until complete healing. Twelve patients were excluded from analysis either because they were lost to follow up after first clinic visit at 2 weeks post op $(\mathrm{N}=7)$ or their underlying etiologies involved a fundamentally different treatment pathway than EAF creation (i.e. $N=5$ patients with CF secondary to diverticulitis that were treated with resection of the involved colon and/or diverting ostomy; $\mathrm{N}=1$ patient with CF secondary to squamous cell carcinoma which was treated primarily with radiation and chemotherapy). Therefore, the final cohort consisted of a total of 99 patients that were assessed for long-term success (Figure 1). Of these, three patients underwent evaluation by MRI for further classification of their fistula because anatomy was not clear at time of clinical evaluation.

\section{Patient demographics:}

As shown in Table 1, the median age at presentation was 46 years (IQR: $37-55$ years), 55\% (54/99) were male, and median Body Mass Index (BMI) was $29 \mathrm{~kg} / \mathrm{m}^{2}$ (IQR: 22-36). Caucasians comprised 78\% of the cohort followed by African Americans (13\%), Asian Americans (7.5\%), and other minorities (1.5\%). Thirty-nine patients $(39.4 \%, 39 / 99)$ underwent anorectal surgery for fistula-in-ano prior to EAF, and the median number of prior fistula procedures was 2 (IQR: 1-2). These previous procedures included fistulotomy/fistulectomy $(33 \%, 33 / 99)$, LIFT (3\%, 3/99), Henley drainage procedure for horseshoe abscess (1\%, $1 / 99)$, and $\operatorname{EAF}(2 \%, 2 / 99)$. The three patients that underwent prior LIFT had documentation within the operative reports of increased technical difficulty while performing EAF due to scarring of the internal anal sphincter and accumulation of granulation tissue. The most common etiologies of fistula-in-ano included cryptoglandular disease (77\%, 76/99), Crohn's disease $(16 \%, 16 / 99)$, UC $(2 \%, 2 / 99)$, radiation injury $(2 \%, 2 / 99)$, indeterminate colitis $(1 \%, 1 / 99)$, obstetric injury $(1 \%, 1 / 99)$, and Hidradenitis Suppurativa $(1 \%, 1 / 99)$.

The Park classification, Garg classification, and St. James classification were used to grade fistula-in-ano and classify fistulas as complex (Table 2). Among the 99 patients, 69 patients (69\%) had abscesses, 12 patients (12\%) had an anterior fistula in female, 5 patients had horseshoe tract, and 7 patients $(7 \%)$ had multiple tracts.

Among 99 patients, a total of 102 EAF procedures were performed, with 3 patients receiving repeat EAF for fistula recurrence. Of the 99 patients that underwent EAF, 93\% (92/99) had successful healing, and 7\% (7/99) experienced recurrence. Of those that had successful healing, $80 \%$ (74/92) experienced healing within 1-2 weeks postoperatively and $20 \%(18 / 92)$ experienced healing by the final postoperative visit without repeat interventions. Among the 7 patients that experienced fistula recurrence, 1 patient was managed conservatively with wound care but remained symptomatic until last follow-up. This patient decided to consult elsewhere following the final visit. The other six patients who had recurrence (6/7, $86 \%)$ required repeat surgery with either fistulectomy $(\mathrm{N}=3)$ or repeat $\mathrm{EAF}(\mathrm{N}=3)$. All 6 of these patients experienced resolution of their symptoms and fistula healing by last date of follow up.

There was a statistically significant lower rate of fistula recurrence in patients who had no history of systemic steroid use as compared with those with a history of taking these medications after EAF ( $P=0.0001$, Table 3$)$. There were no significant differences in recurrence rates when comparing between different age, race, gender, BMI, history of smoking, other chronic 
comorbidities ( $P>0.05$ for all). On performing subgroup analysis, patients without a history IBD had a successful healing rate of $98 \%$ (78/80), compared to patients with IBD $(73.6 \%, 14 / 19),(P<0.0001)$.

At date of last clinic follow up, 3\% (3/99) of patients complained of fecal incontinence; however, 2/3 had complained of fecal incontinence pre-operatively. For the patient who developed new-onset fecal incontinence, their fistula was secondary to hidradenitis suppurativa, and symptoms were improved stool bulking agents by date of last follow up at 7 months postoperatively. Patients who developed fecal incontinence after EAF were documented to have significant scarring at the time of surgery, as per operative records.

\section{Discussion}

Many studies discuss the limited descriptive data on CF populations who undergo EAF. ${ }^{1,2}$ At present, there is still no clear definition of a "typical" patient with this pathology, and it is unclear if the results from this series can be applied to other populations. Traditional EAF is known to have a recurrence rate of 7-48\% in patients with CFs. $1,2,21$ Other treatment options available to treat fistulas-in-ano include VAAFT surgery, which has an overall recurrence rate of $15.8 \% 22$, and LIFT, a sphincter sparing technique that has gained popularity recently due to high success rates of $76 \%$ for complex anal fistula 23 . Also, worth mentioning is the FiLAC which another sphincter saving procedure, has an overall success rate of $69 \%$ for fistula-in-ano. ${ }^{10}$

This study reports a relatively large cohort of patients with complex anal rectal fistulas undergoing EAF by using transverse imbrication of the internal sphincter over the internal fistula opening. Our modification of EAF demonstrates a much lower recurrence rate of $7 \%$. Additionally, the rate of postoperative fecal incontinence (1\%) is low compared to other studies (15$20 \%) .{ }^{1,2,21}$ These results can potentially be explained by a modification which securely closes the opening of the fistula, while eliminating tension from the flap. Our cohort consisted of patients with various etiologies of CFs such as cryptoglandular disease, Crohn's disease, UC, radiation, and obstetric trauma. ${ }^{1,2}$ Among this diverse population, there was a recurrence-free rate of $93 \%$, making this study relatively large, with short-term success that would needs to be corroborated by long-term follow up. ${ }^{1,2,21}$

\section{Limitations}

Indeed, one of the limitations of this study is the five patients who were lost to follow up, which represents a significance source of selection bias commonly found in retrospective reviews. Additionally, there was relatively short term follow up in our patients (median of 6.6 months), which limits the confidence with which this approach can be recommended for definitive fistula treatment. An important future direction for advancing the treatment of this condition is performing closure follow-up with patients who otherwise did not return for post-operative care, as well as continued surveillance and outcome reporting over long-term follow up of at least a year. Finally, patients were studied from a single center with a single surgeon team leader, thus limiting the generalizability of the results based on variance in surgeon technique and population of patients.

Additionally, pre-operative imaging was not routinely performed, and it is possible that routine imaging by MRI would provide more accurate classification and perioperative planning of CFs. Furthermore, a formal fecal incontinence assessment scale was not routinely used in pre- and post-operative clinical assessment, which limits the accuracy of the assessment of fecal incontinence and will be considered for future study to more accurately assess the degree of symptoms of incontinence and whether they were present pre-operatively. In this cohort, more severe scarring likely resulted in more extensive dissection and, therefore, increased risk of sphincter involvement. Further study of these patients would be required to see how much this new-onset fecal incontinence was impacting their lives, and if it was an improvement over their original fistula symptoms. 
Further research is needed to compare this modified EAF procedure to other approaches, such as a traditional figure-of-8 closure or no suture closure, or those involving flaps with partial or full-thickness internal sphincter components. These efforts might better delineate which modifications of the EAF procedure would result in a higher success rates. Furthermore, comparisons between various EAF modifications and other sphincter-sparing procedures, such as fibrin glue, ${ }^{20}$ stem cell pastes $^{14}$, and more invasive surgical procedures such as LIFT and VAAFT ${ }^{8,9}$ are needed to optimize treatment planning for those at high risk of incontinence.

\section{Conclusion}

The study a modified EAF procedure along with outcomes of fistula recurrence and new-onset fecal incontinence. This novel technique shows low recurrence (7\%) and new-onset incontinence rates (1\%) in a 6.6 month follow up period, suggesting that it seems to be a valid treatment option of CFs. Additional long-term studies are needed to compare this modification with the traditional EAF technique, and with other treatment types for CFs.

\section{Abbreviations}

BMI: Body mass index, CF: Complex fistulas, EAF: Endorectal advancement flap, EUA: Exam Under Anesthesia, FiLAC: Fistula Laser Closure, IQR: interquartile range, LIFT: Ligation of intersphincteric tract, UC: Ulcerative colitis, VAAFT: video-assisted anal fistula treatment, MRI: Magnetic Resonance Imaging

\section{Declarations}

- Ethics approval and consent to participate:

This study was approved on October 7, 2019 by the Internal Review Board of Oakland University- William Beaumont Hospital Health Care System, Royal Oak, MI under protocol \# 2019-233, Category 4

- Consent for publication: Not applicable.

- Availability of data and materials:

The datasets used and/or analyzed during the current study are available from the corresponding author on reasonable request. Availability of data was obtained after IRB approval under protocol \# 2019-233.

- Competing interest:

The authors declare that they have no competing interests.

- Funding:

Funding was not required for the production of this study, nor the manuscript preparation. All authors therefore have no declarations of funding sources.

- Authors' contributions

Both HT and EB contributed equally to this work; both provided concept, data collection, data analysis and manuscript drafting.

KS: Provided data analysis

GD: Provided manuscript drafting and final revisions

All authors read and approved the final manuscript. 
Acknowledgement: Maya Deshmukh, MD for figures drawing.

\section{Authors information:}

Hassan Al-Turaihi: Case Western Reserve University, Department of Colon and Rectal Surgery, 11100 Euclid Ave. Lakeside 7, Cleveland, Ohio, 44106

Elizabeth Blears: Allegheny Health Network, Department of Colorectal Surgery, 320 East North Ave, Pittsburgh, PA, 15212 Kavin Sugumar: Case Western Reserve University, Department of Colon and Rectal Surgery, 11100 Euclid Ave. Lakeside 7, Cleveland, Ohio, 44106

Ganesh Deshmukh: Oakland University William Beaumont School of Medicine, Department of Colon and Rectal Surgery, 3601 W 13 Mile Rd, Royal Oak, MI 48073

\section{References}

1. Balciscueta Z, Uribe N, Balciscueta I, Andreu-Ballester JC, García-Granero E. Rectal advancement flap for the treatment of complex cryptoglandular anal fistulas: a systematic review and meta-analysis. International journal of colorectal disease. 2017;32(5):599-609. doi:10.1007/s00384-017-2779-7

2. Gottgens K, Smeets R, Stassen L, Beets G, Breukink S. Systematic review and meta-analysis of surgical interventions for high cryptoglandular perianal fistula. Int J Colorectal Dis. 2015;30(5):583-593. doi:10.1007/s00384014-2091-8

3. Jayarajah U, Wickramasinghe DP, Samarasekera DN. Anal incontinence and quality of life following operative treatment of simple cryptoglandular fistula-in-ano: a prospective study. BMC Research Notes. 2017;10(1):572. doi:10.1186/s13104-017-2895-z

4. Visscher AP, Schuur D, Roos R, van der Mijnsbrugge GJH, Meijerink WJHJ, Felt-Bersma RJF. Long-term Follow-up After Surgery for Simple and Complex Cryptoglandular Fistulas. Diseases of the Colon \& Rectum. 2015;58(5):533-539. doi:10.1097/DCR.0000000000000352

5. Parks AG, Gordon PH, Hardcastle JD. A classification of fistula-in-ano. British Journal of Surgery. 1976;63(1):1-12. doi:10.1002/bjs.1800630102

6. Lewis RT, Maron DJ. Anorectal Crohn's Disease. Surgical Clinics of North America. 2010;90(1):83-97. doi:10.1016/j.suc.2009.09.004

7. Stellingwerf ME, van Praag EM, Tozer PJ, Bemelman WA, Buskens CJ. Systematic review and meta-analysis of endorectal advancement flap and ligation of the intersphincteric fistula tract for cryptoglandular and Crohn's high perianal fistulas. BJS Open. 2019;3(3):231-241. doi:10.1002/bjs5.50129

8. Meinero P, Mori L. Video-assisted anal fistula treatment (VAAFT): a novel sphincter-saving procedure for treating complex anal fistulas. Techniques in coloproctology. 2011;15(4):417-422. doi:10.1007/s10151-011-0769-2

9. Schwandner O. Video-assisted anal fistula treatment (VAAFT) combined with advancement flap repair in Crohn's disease. Techniques in Coloproctology. 2013;17(2):221-225. doi:10.1007/s10151-012-0921-7

10. Elfeki H, Shalaby M, Emile SH, Sakr A, Mikael M, Lundby L. A systematic review and meta-analysis of the safety and efficacy of fistula laser closure. Techniques in Coloproctology. 2020;24(4):265-274. doi:10.1007/s10151-020-02165-1

11. Hilsabeck JR. Transanal advancement of the anterior rectal wall for vaginal fistulas involving the lower rectum. Diseases of the Colon \& Rectum. 1980;23(4):236-241. doi:10.1007/BF02587089

12. Dudukgian $\mathrm{H}, \mathrm{Abcarian} \mathrm{H}$. Why do we have so much trouble treating anal fistula? World journal of gastroenterology. 2011;17(28):3292-3296. doi:10.3748/wjg.v17.i28.3292 
13. Christoforidis D, Pieh MC, Madoff RD, Mellgren AF. Treatment of Transsphincteric Anal Fistulas by Endorectal Advancement Flap or Collagen Fistula Plug. Diseases of the Colon \& Rectum. 2009;52(1):18-22.

doi:10.1007/DCR.0b013e31819756ac

14. Herreros MD, Garcia-Arranz M, Guadalajara H, De-La-Quintana P, Garcia-Olmo D. Autologous Expanded AdiposeDerived Stem Cells for the Treatment of Complex Cryptoglandular Perianal Fistulas. Diseases of the Colon \& Rectum. 2012;55(7):762-772. doi:10.1097/DCR.0b013e318255364a

15. ELTING AW. THE TREATMENT OF FISTULA IN ANO. Annals of Surgery. 1912;56(5):726-752. doi:10.1097/00000658191211000-00010

16. Aguilar PS, Plasencia G, Hardy TG, Hartmann RF, Stewart WRC. Mucosal advancement in the treatment of anal fistula. Diseases of the Colon \& Rectum. 1985;28(7):496-498. doi:10.1007/BF02554093

17. Garg P. Comparing existing classifications of fistula-in-ano in 440 operated patients: Is it time for a new classification? A Retrospective Cohort Study. International Journal of Surgery. 2017;42:34-40. doi:10.1016/j.ijsu.2017.04.019

18. Garg P. Is fistulotomy still the gold standard in present era and is it highly underutilized?: An audit of 675 operated cases. International Journal of Surgery. 2018;56:26-30. doi:10.1016/j.ijsu.2018.06.009

19. Parks AG. Advances in the surgery of the colon and rectum. The Practitioner. 1968;201(204):669-675. http://ovidsp.ovid.com/ovidweb.cgi?T=JS\&PAGE=reference\&D=med1\&NEWS=N\&AN=4879616

20. Morris J, Spencer JA, Ambrose NS. MR imaging classification of perianal fistulas and its implications for patient management. Radiographics. 2000;20(3):623-635. doi:10.1148/radiographics.20.3.g00mc15623

21. Lee C-L, Lu J, Lim T-Z, et al. Long-term outcome following advancement flaps for high anal fistulas in an Asian population: a single institution's experience. International journal of colorectal disease. 2015;30(3):409-412. doi:10.1007/s00384-014-2100-y

22. Emile SH, Elfeki H, Shalaby M, Sakr A. A Systematic review and met-analysis of the efficacy and safety of videoassisted anal fistula treatment (VAAFT). Surgical Endoscopy. 2018;32(4):2084-2093. doi:10.1007/s00464-017-5905-2

23. Emile SH, Khan SM, Adejumo A, Koroye O. Ligation of intersphincteric fistula tract (LIFT) in treatment of anal fistula: An updated systematic review, meta-analysis, and meta-regression of the predictors of failure. Surgery. 2020;167(2):484-492. doi:10.1016/j.surg.2019.09.012

\section{Tables}

Table 1: Patient Demographics 
Demographics $(\mathbf{N}=99)$

Parameter

Age, years

Gender

Male

Female

Race

White

Black

Asian

Other

BMI, $\mathrm{kg} / \mathrm{m} 2$

Follow-up period

Incontinence present before surgery

History of previous surgeries

Previous fistula repair
Median with interquartile range or $\mathrm{n}$ (\%)

$46(37-55)$

$54 / 99$ (55\%)

$45 / 99$ (45\%)

$64 / 82(78 \%)$

$11 / 82(13 \%)$

$6 / 82(7.5 \%)$

$1 / 82(1.5 \%)$

$29(22-36)$

6.6 (3.3-24 months)

$5 / 99(5 \%)$

91/99 (92\%)

$39 / 99(39.4 \%)$

\section{Previous Perianal Surgeries (\% patients who underwent a given procedure previously)}

Fistulectomy with or without debridement

Ligation of Inter-sphincteric Tract (LIFT)

Henley drainage procedure

Redo-advancement (previous)

Number of previous procedures
33/99 (33\%)

3/99 (3\%)

$1 / 99(1 \%)$

$2 / 99(2 \%)$

$2(1-2)$

\section{Underlying Diagnosis}

Cryptoglandular disease

Crohn's Disease

Ulcerative Colitis

Radiation Injury

Indeterminate colitis (IBD)

Obstetric Injury

Hidradenitis Suppurativa
76/99 (77\%)

$16 / 99$ (16\%)

$2 / 99(2 \%)$

$2 / 99(2 \%)$

$1 / 99(1 \%)$

$1 / 99(1 \%)$

$1 / 99(1 \%)$

\section{Co-morbidities}

Systemic immunomodulator, steroid or chemotherapy 13/99 (13\%) use

Active Smoker/ Former Smoker

13/99 (14\%), 5/99 (5.5\%)

Diabetes Mellitus -Type 2

$12 / 99(12 \%)$

Chronic Obstructive Pulmonary Disease 
Congestive Heart Failure

Coronary Artery Disease

Hypertension

Chronic kidney disease
$7 / 99(7 \%)$

9/99 (9\%)

32/99 (32\%)

$1 / 99(1 \%)$

Table 2. Grading of fistula-in-ano

\begin{tabular}{|c|c|c|c|c|c|c|}
\hline Grade & $\begin{array}{l}\text { Park's } \\
\text { classification }\end{array}$ & $\begin{array}{l}\text { Frequency } \\
(\%)\end{array}$ & $\begin{array}{l}\text { St. James } \\
\text { classification }\end{array}$ & $\begin{array}{l}\text { Frequency } \\
(\%)\end{array}$ & Garg's classification & $\begin{array}{l}\text { Frequency } \\
(\%)\end{array}$ \\
\hline $\mathrm{I}$ & Intersphincteric & $0(0 \%)$ & $\begin{array}{l}\text { Simple } \\
\text { intersphincteric }\end{array}$ & 0 & $\begin{array}{l}\text { Low fistula with linear } \\
\text { tract }\end{array}$ & 0 \\
\hline II & Transsphincteric & $\begin{array}{l}80 / 99 \\
(80 \%)\end{array}$ & $\begin{array}{l}\text { Complex } \\
\text { intersphincteric }\end{array}$ & 0 & $\begin{array}{l}\text { Low fistula with } \\
\text { multiple tracts }\end{array}$ & 0 \\
\hline III & Supralevator & $5 / 99(5 \%)$ & $\begin{array}{l}\text { Simple } \\
\text { Transphincteric }\end{array}$ & 0 & $\begin{array}{l}\text { High transsphincteric } \\
\text { with linear tract }\end{array}$ & $\begin{array}{l}75 / 99 \\
(6 \%)\end{array}$ \\
\hline IV & Extrasphincteric & $\begin{array}{l}14 / 199 \\
(14 \%)\end{array}$ & $\begin{array}{l}\text { Complex } \\
\text { transsphincteric }\end{array}$ & $\begin{array}{l}80 / 99 \\
(80 \%)\end{array}$ & $\begin{array}{l}\text { High transsphincteric } \\
\text { with multiple tracts }\end{array}$ & $5 / 99(5 \%)$ \\
\hline V & - & - & $\begin{array}{l}\text { Suprasphincteric } \\
\text { or } \\
\text { extrasphincteric }\end{array}$ & $\begin{array}{l}19 / 99 \\
(20 \%)\end{array}$ & $\begin{array}{l}\text { High transsphincteric } \\
\text { with intersphincteric } \\
\text { extension or } \\
\text { supra/extrasphincteric } \\
\text { fistula }\end{array}$ & $\begin{array}{l}19 / 99 \\
(19 \%)\end{array}$ \\
\hline
\end{tabular}

Table 3: Factors associated with Success vs Recurrence after Endoadvancement Flap 


\begin{tabular}{|l|l|l|l|}
\hline Parameter & $\begin{array}{l}\text { Initial Successful EAF } \\
(\mathrm{N}=92)\end{array}$ & $\begin{array}{l}\text { Recurrence } \\
(\mathrm{N}=7)\end{array}$ & P-value \\
\hline Age (years) ${ }^{+}$ & $47(15-77)$ & $38(25-68)$ & 0.42 \\
\hline Gender & & & \\
\hline Male & $48 / 92(52 \%)$ & $6 / 15(85 \%)$ & \\
\hline Female & $44 / 92(48 \%)$ & $1 / 15(15 \%)$ & 0.08 \\
\hline Race & & & \\
\hline White & $58 / 76(76.3 \%)$ & $4 / 6(68 \%)$ & 0.61 \\
\hline Black & $11 / 76(14.5 \%)$ & $1 / 6(16 \%)$ & \\
\hline Asian & $6 / 76(7.9 \%)$ & $1 / 6(16 \%)$ & \\
\hline Other & $1 / 76(1.3 \%)$ & $0 / 6(0 \%)$ & \\
\hline BMI (median, IQR) kg/m $\left.{ }^{2}\right)^{+}$ & $29(25-32)$ & $33(18-35)$ & 0.15 \\
\hline $\begin{array}{l}\text { Systemic immunomodulator, steroid or } \\
\text { chemotherapy use }\end{array}$ & $9 / 92(9 \%)$ & $4 / 7(57 \%)$ & $0.0001 *$ \\
\hline Active Smoker or former Smoker & $16 / 91(17.6 \%)$ & $2 / 7(28.6 \%)$ & 0.46 \\
\hline Diabetes Mellitus Type 2 & $11 / 92(12 \%)$ & $1 / 7(14 \%)$ & 0.1 \\
\hline Chronic Obstructive Pulmonary Disease & $5 / 92(5.4 \%)$ & \multicolumn{1}{|c|}{$0 / 7(0 \%)$} & 0.52 \\
\hline Congestive Heart Failure & $6 / 92(6.5 \%)$ & $1 / 7(14.3 \%)$ & 0.44 \\
\hline Coronary Artery Disease & $8 / 92(8.7 \%)$ & $1 / 7(14.3 \%)$ & 0.62 \\
\hline Hypertension & $29 / 92(31.5 \%)$ & $3 / 7(42 \%)$ & 0.53 \\
\hline Inflammatory bowel disease & $14 / 92(15 \%)$ & $5 / 7(71.4 \%)$ & $<0.0001 *$ \\
\hline Total \# prior procedures ${ }^{+}$ & $2(1-2)$ & $2(2-3)$ & 0.62 \\
\hline Required diverting stoma & $3 / 92(3.2 \%)$ & $0 / 7(0 \%)$ & 0.62 \\
\hline
\end{tabular}

+Median with interquartile range

*Statistically significant $(\mathrm{P}<0.05)$

\section{Figures}




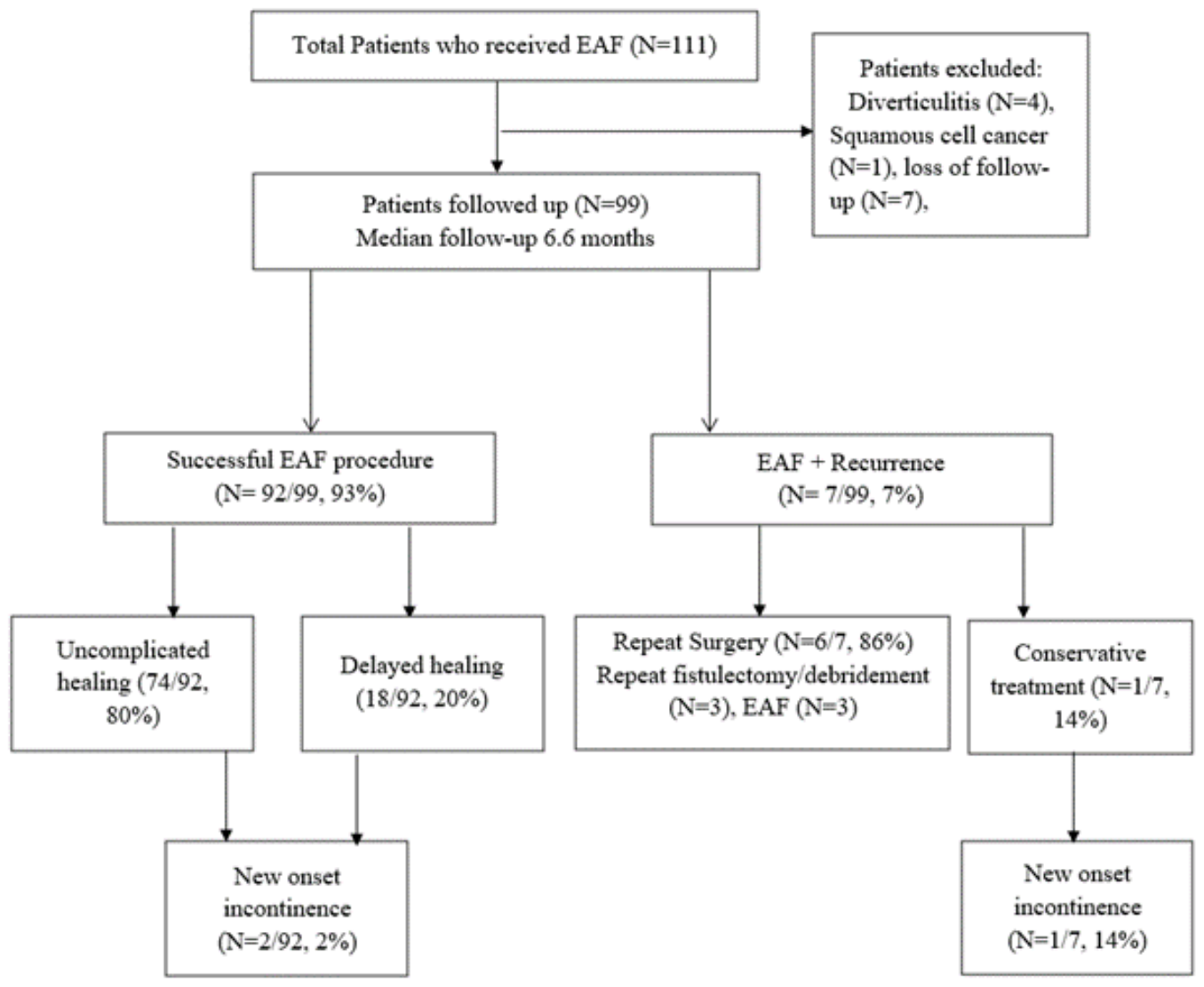

Figure 1

Study flow diagram

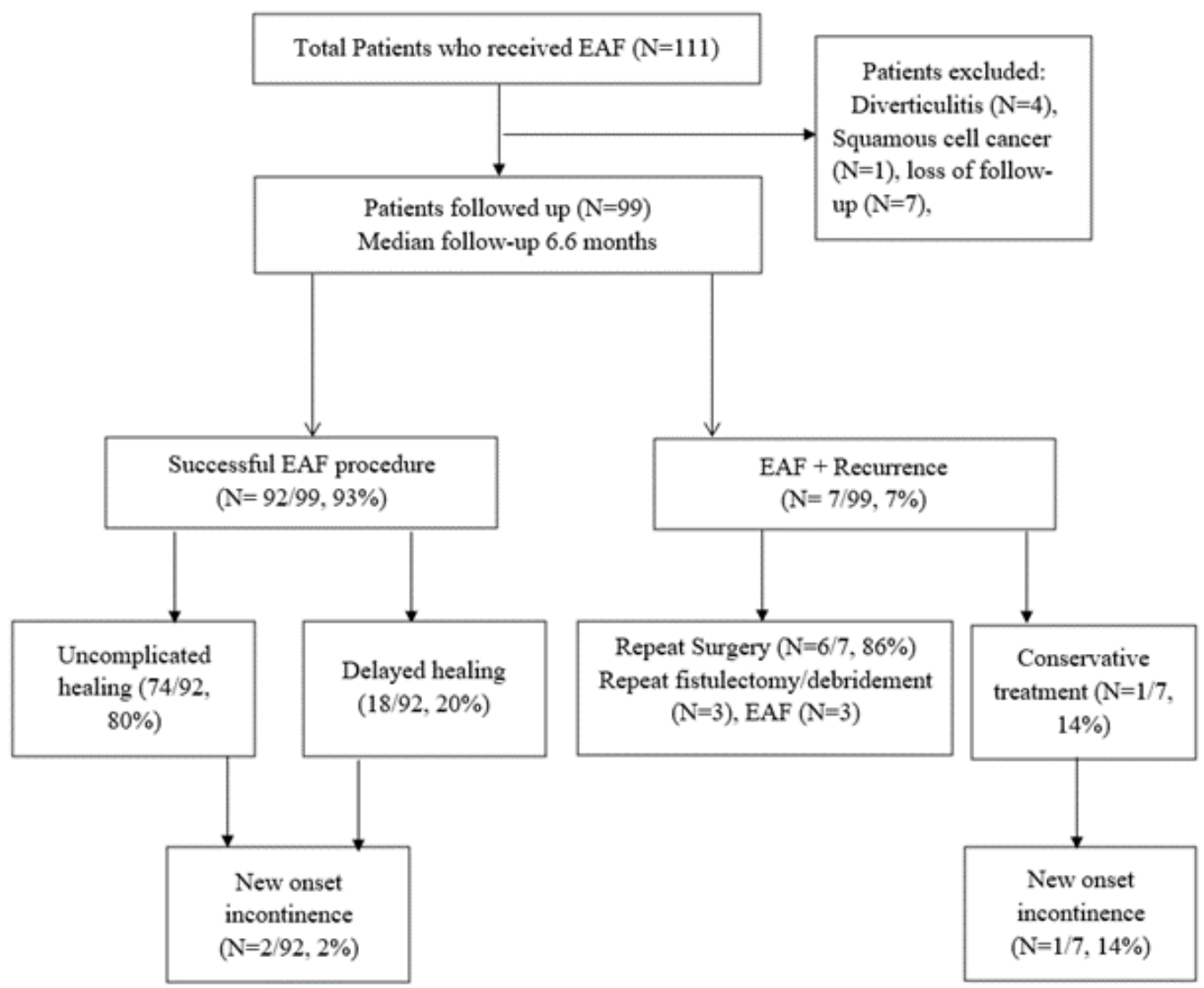


Figure 1

Study flow diagram

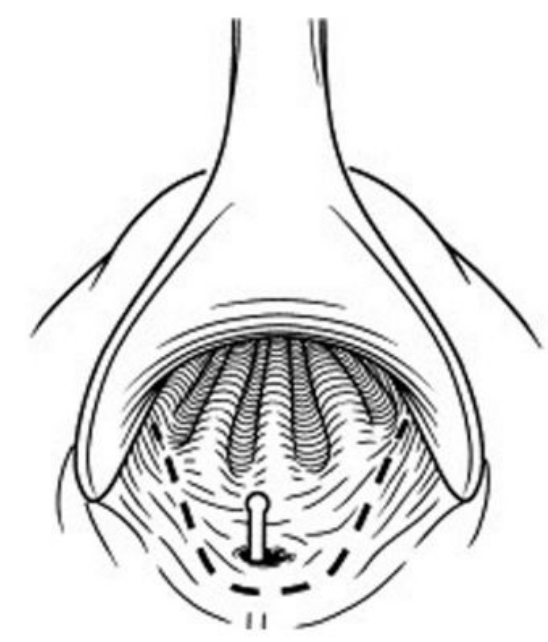

Figure 2A

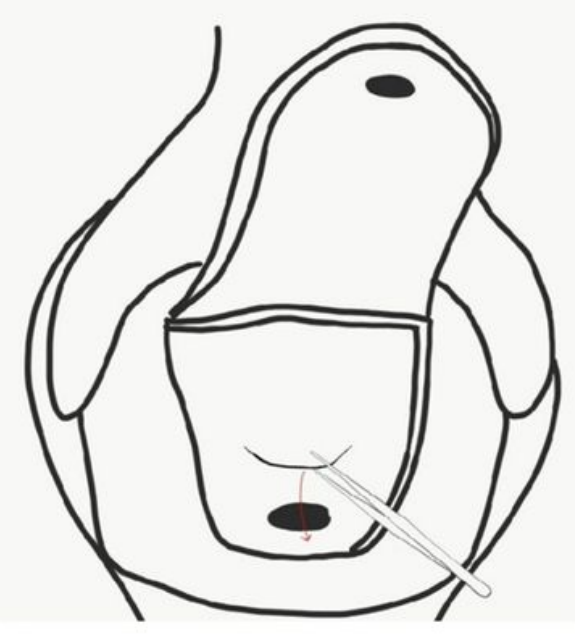

Figure 2 B

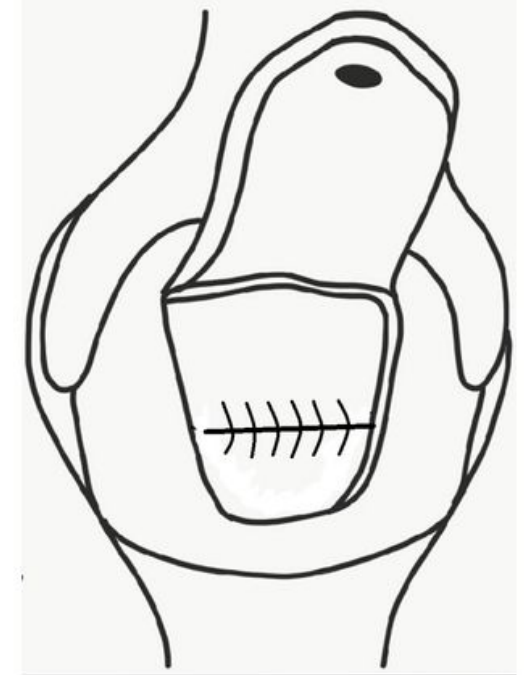

Figure $2 \mathrm{C}$

Figure 2

A, B: Technique of creating the flap, C, Internal fistula opening closure in a transverse fashion.

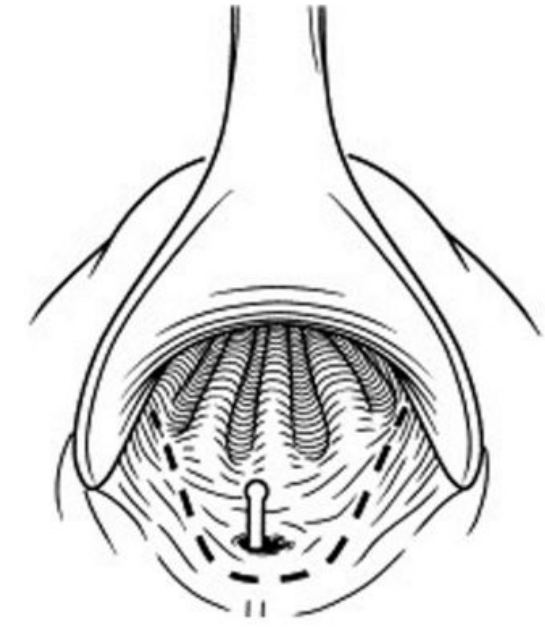

Figure 2A

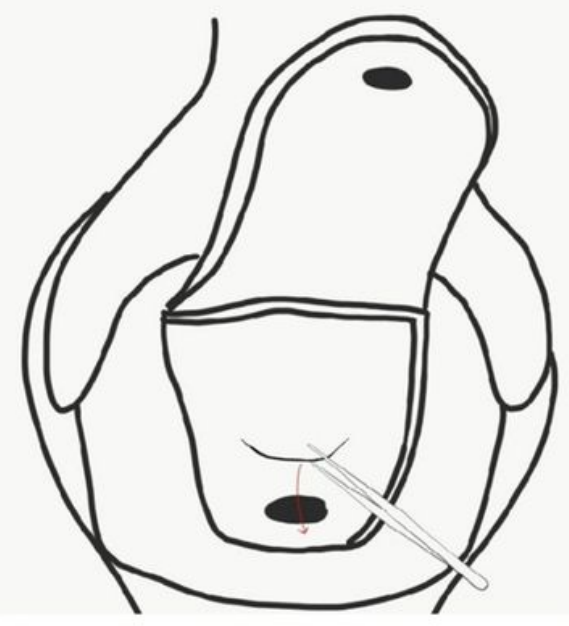

Figure 2 B

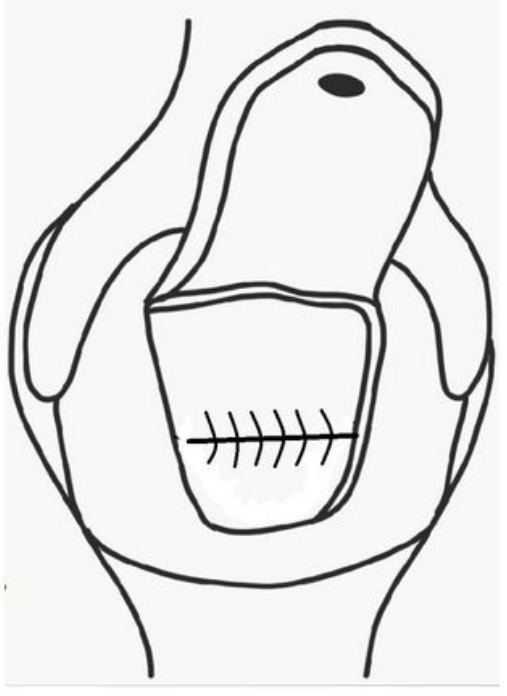

Figure $2 \mathrm{C}$

Figure 2

A, B: Technique of creating the flap, $C$, Internal fistula opening closure in a transverse fashion. 


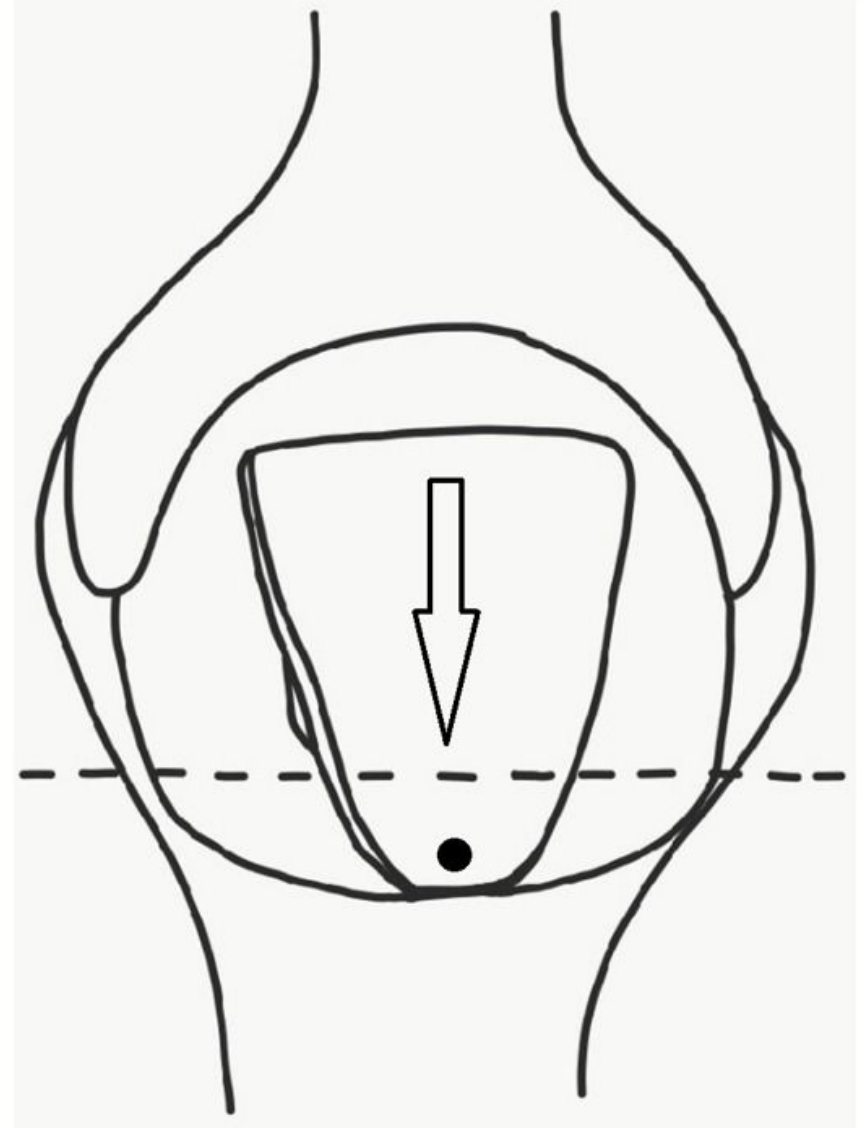

Figure $3 \mathrm{~A}$

Figure 3

A, B: Flap closure.

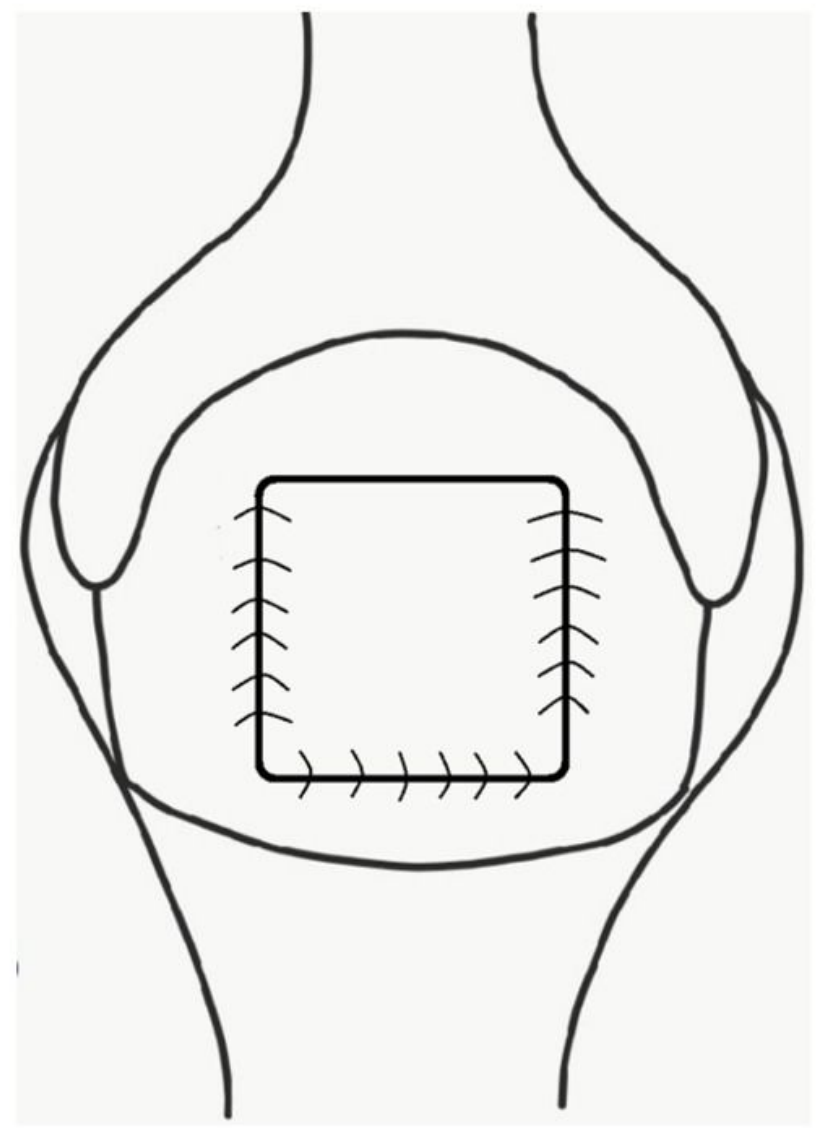

Figure 3 B 


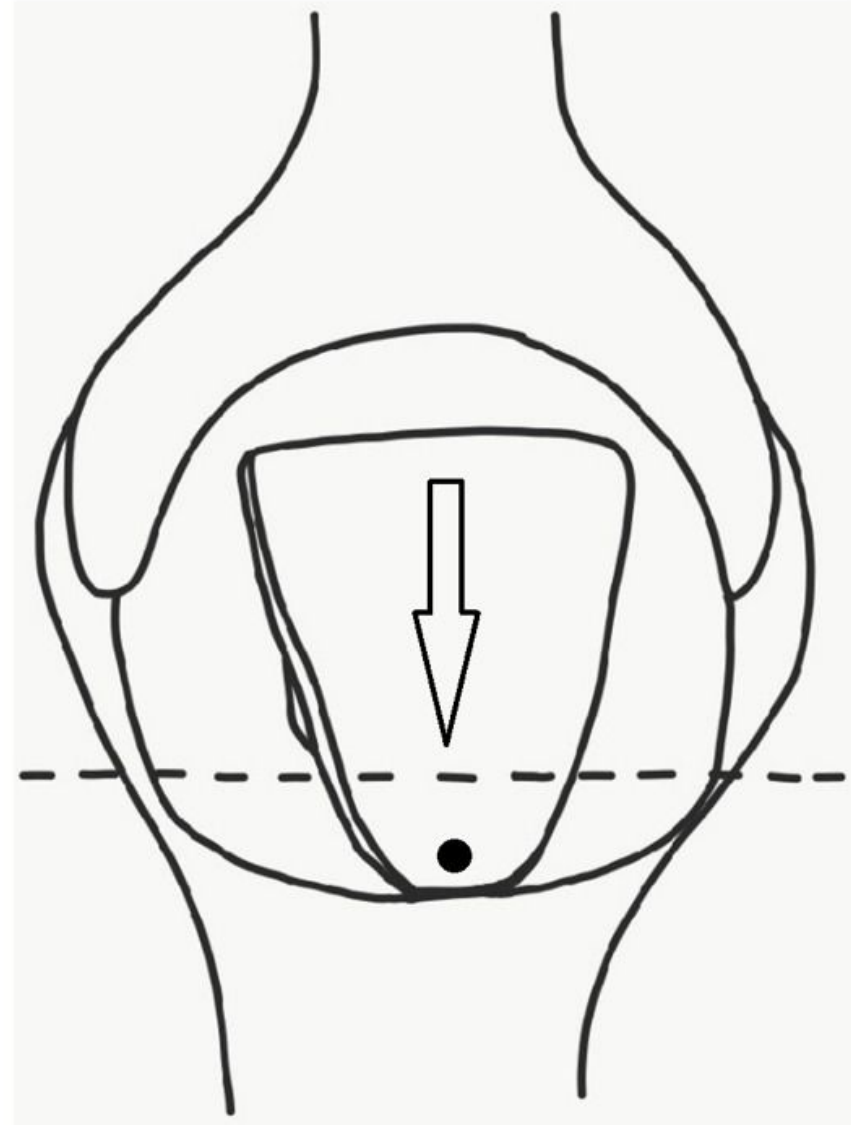

Figure $3 \mathrm{~A}$

Figure 3

A, B: Flap closure.

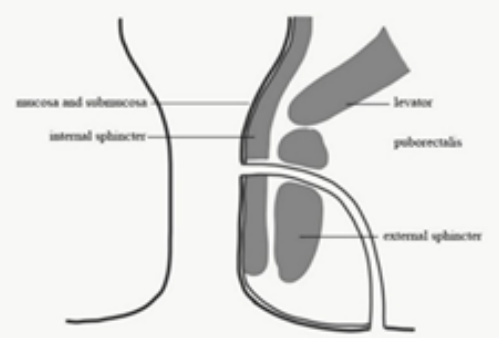

A

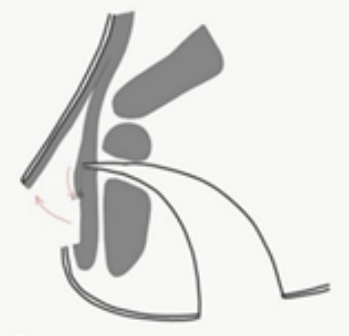

B

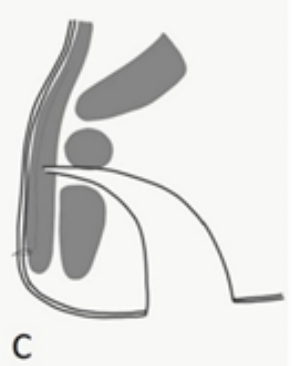

Figure 4

A, B, C: Internal fistula opening, Coring out external Opening and flap closure. (Sagittal view) 


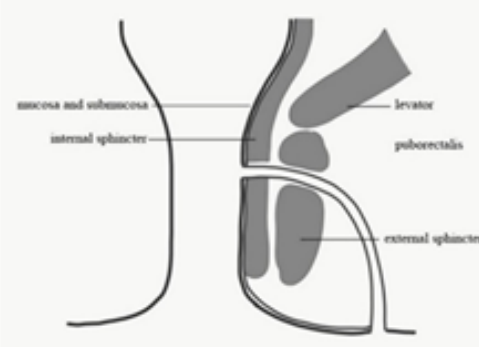

A

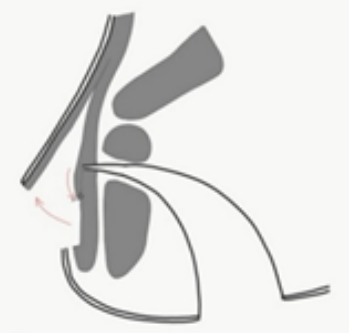

B

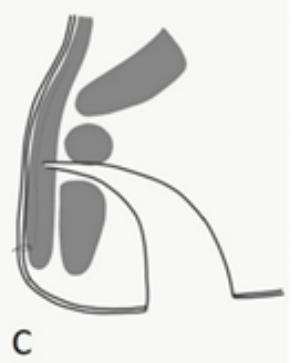

\section{Figure 4}

A, B, C: Internal fistula opening, Coring out external Opening and flap closure. (Sagittal view) 